\title{
THERMAL SPRINGS AND SOCIAL DISTRIBUTION OF GROUND WATER
}

\author{
ALEJANDRO ACOSTA COLLAZO \\ Architecture Department, Autonomous University of Aguascalientes, Mexico
}

\begin{abstract}
Thermal springs are an essential source of water for certain towns. Since human beings depend on water, different ways to distribute it were developed. In Mexico, aqueducts became an important means to conduct water to society once the Spaniards decided to found new settlements in America, and through the years knowledge in architecture and urbanism have contributed to improve tunnels, water boxes, thermal baths, fountains and modern water infrastructure. A good example is the city of Aguascalientes - which means "hot waters" in English - located in the central part of the country. Hot springs have been used as a source of water since the 16th century, but nowadays water tunnel distribution systems show deficiencies in response to urban growth. The main objective of the paper is to analyse social ground water distribution in the city of Aguascalientes, from the Ojocaliente thermal baths being built in 1831 to modern day drinking water distribution. So, it's through an historical analysis of Aguascalientes City, the use of a survey and a qualitative statistical method that we can understand urban morphology and the way inhabitants in a Mexican city perceive social ground water distribution. The way drinking water used to be distributed into the city is described in the paper. Also, the use of a correspondence analysis will be helpful to understand the perception that people have that water coming from taps isn't clean now. This situation has given advantages to distribution of bottled fresh water recently. Social ground water distribution in Aguascalientes has contributed to shape the city since the 19th century, even though recently drinking water distribution is bottled and expensive. Also, publicity made abroad related to unclean water management, like: Don't drink the water! has an impact on tourists and city visitors who distrust Aguascalientes ground water quality.
\end{abstract}

Keywords: water distribution, hot springs, society, historic water supply buildings.

\section{INTRODUCTION}

The main objective of this paper is to accomplish an analysis of social ground water distribution, including historic water buildings in the city, since the Ojocaliente thermal baths were built in the year of 1831. In fact, when the first settlements occurred during the 16th century the thermal springs were used to take water from this source and it was distributed since then - by irrigation ditches - to the main square of the small village, and also nowadays thermal waters from such source is still distributed through a complex built environment. So, it's been more than four centuries since social thermal water distribution has taken place in Aguascalientes.

Thermal springs and social distribution of ground water is barely analysed by researchers in Mexico, but in this paper it will be explained, starting from simple irrigation ditches to water supply buildings and distribution of drinking water to the population of the town. A qualitative progress in the way water was distributed occurred during the 20th century. Therefore, instead of using donkeys or mules to pull the fresh water tanks on wheels, small water companies preferred to use fresh water trucks during the second half of the 20th century, and also water distribution was improved during the beginning of the 21 st century.

Hence, people's opinion on fresh water distribution nowadays was useful to understand if public image about water depends on publicity or to appreciate what they know about water quality. 


\section{METHODOLOGY}

The first step in the methodology applied in this article was the use of an historical analysis about social distribution of ground water, in order to understand the qualities of the social problem. Afterwards, a survey and a qualitative statistical method were very useful to understand urban morphology and the way inhabitants in a Mexican city perceive the use of ground water distribution. So, it was convenient to design a survey including opinions of people, using direct questions about historical use of water and nowadays opinions about bottled water distribution. The survey included a questionnaire plus the following categories with statistical validity: Age; gender; educational level; origin; trust in city's tap water; water supply system evaluation; disappearance of public drinking fountains; conscious about El Cedazo water tunnel; awareness about water distribution to old orchards; reasons of consuming bottled water and reasons people don't drink tap water. Next step was operating the survey at public places. Downtown is the most visited place in the city, and also it was easier for the surveyors to find people willing to answer the survey there. At the time doing the survey, a good spot to find respondents was a touristic bus stop. Also, some other good spots were outside the main museums or outside the main historic buildings of town. Five surveyors applied 150 questionnaires apiece. The total amount of questionnaires was 650, and they were completed during the first week of August. But, a sample of 125 questionnaires was chosen using a random method. This is, 25 questionnaires respectively. After obtaining the results, a qualitative statistical method was used. The categories of the questionnaire and the variables obtained were used in multiple correspondence analyses. The correspondence among variables helped clarified configuration of interactions. The Burt's matrix was successfully used to obtained valid relationships. In Fig. 1 we can observe an illustration of how a Burt's matrix runs. It's through categories of the questionnaires' data and the order of variables that we can obtain a correspondence analysis. A complete explanation of how to obtain a Burt's matrix can be examined in Acosta Collazo [1].

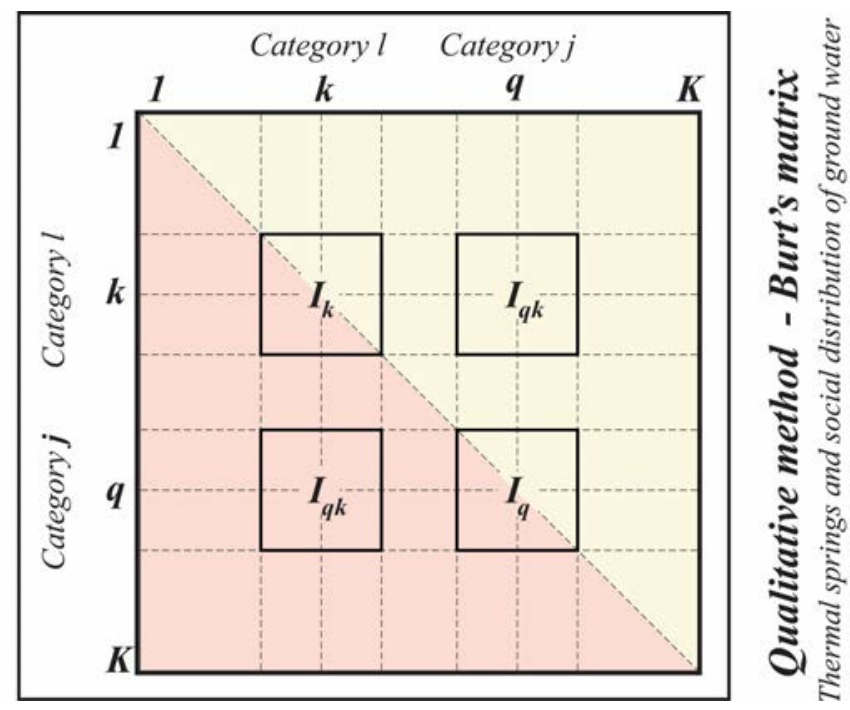

Figure 1: Qualitative method based on a multiple correspondence analysis, specifically a Burt's matrix. Accordingly, an interaction of variables in categories of a survey. (Source: Author research design, August, 2019 and a reinterpretation of a figure exposed by Josse et al. [2].) 


\section{HISTORIC WATER SUPPLY BUILDINGS IN AGUASCALIENTES}

In order to cover the distance from the water thermal main sources (Ojocaliente) to the main fountains in the city centre, water ditches were used at the beginning. Culture of high society during the 19th century in Aguascalientes included taking baths and swimming at Ojocaliente Thermal Baths, but poor people decided to take baths in the open water ditches; consequently, such water wasn't that clean because it had been used by humans at the thermal springs before flowing into the water ditches. Ruiz López talks about this situation in her studies about poor people between the years: 1871 and 1942 in Aguascalientes City, and the way reach people tried to civilize them [3].

The water is warm at the main source of the thermal springs in Ojocaliente Baths. The average temperature is about $40^{\circ} \mathrm{C}\left(104^{\circ} \mathrm{F}\right)$. In regular conditions it's too hot for swimming pools and baths, so in most of the cases the baths and the citizens at home combine hot water with cold water to regulate the temperature. Also, there used to be a well-known baths named Los Arquitos in the city, and the hot water system included water tanks to regulate the temperature of water coming from Ojocaliente hot springs and baths. Also, the neighbourhoods near the Ojocaliente thermal springs use subsoil water and it's also hot. For this reason, some people in their houses prefer to connect their water pipes with spring water directly to showers in order to avoid heating it with boilers. As a result, they save energy and money. Most of the citizens say it's worth it. So, living in houses around Ojocaliente thermal springs, and also in some areas of the city centre, has advantages over the rest of the city.

Fig. 2 shows part of a restoration project of the Caracol water box done by the author of this article in the year of 2001. It's situated by Ojocaliente thermal springs, but in this case the water was collected by natural subsoil filtration, so the water wasn't as hot as in the thermal springs. This water box was the source of a distribution system to the southern part of the city during the late 19th century, and also at the beginning of the 20th century. Also, this water was conducted through a subsoil tunnel directly to several fountains and to the old orchards situated in that area.

The objective of explaining how this water box used to function is to show the importance of this building for the history of water distribution in Aguascalientes. Even though, it looks like a simple cylinder shaped building, with a distinctive beige patina, the way it conducted water was remarkable and also complex. The building had a spiral stone staircase. After the making of the project the cylindrical building was actually restored - including its staircase.

The water box had an entrance below from water filtration underneath the building and also from a water table filtered by sedimentary rocks (see Fig. 2), composed of petrosilex material. In fact, this is the main reason the place was named El Cedazo (a water filter). Furthermore, petrosilex is a type of sedimentary rock that was used in prehistoric times for making tools. In fact, near the water box was discovered several decades ago a prehistoric place, and after getting through with the restoration of the building local tourism agencies had artists reconstruct prehistoric animals like sabre-toothed tigers, mammoths, glyptodonts, giant armadillos, American mastodons, etc. in fiberglass, to recreate the way the place looked like before human history, several thousand years ago.

Guzmán Gutiérrez and Acosta Rincón mention: in the year of 1974 the palaeontologist Walter W. Delquest described new species of animals like the antelope that lived in the Cedazo river in Aguascalientes, and named it Tetrameryx mooseri, honouring Oswaldo Mooser Barandun [4] the scientist who did a great job doing paleontological research in Aguascalientes. The recreation of prehistoric animals and the importance of the water box restoration became an attractive site to visit during the last decade. 


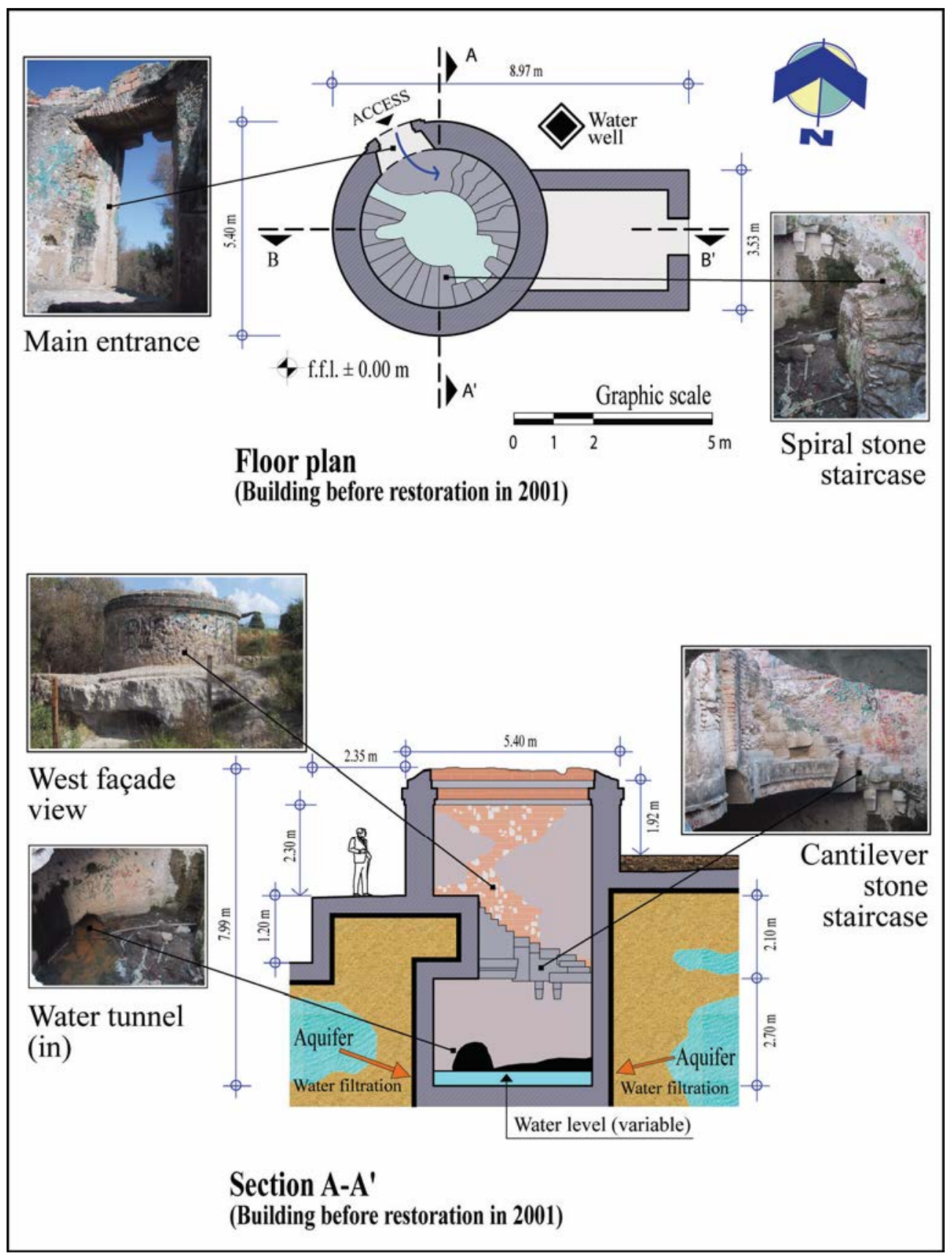

Figure 2: The Caracol water box. Floor plan and Section A-A'. (Source: Restoration project, photos and drawing by Alejandro Acosta Collazo originally in 2001. Drawing edition: Alejandro Acosta Colunga, August 2019.) 
The Caracol somehow functioned like a water filter and then the water was conducted through a tunnel (out) that can be seen in Fig. 3. During the restoration project it was discovered a well-constructed tunnel with stonewalls. The masonry construction was made with a material named "matacán". The stone looks like "tepetate" (Nahuatl tepetate), which is found near volcanic regions in Mexico, so the material doesn't absorb water. The tunnel coming out from the Caracol building was named El Cedazo tunnel, and it distributed ground water to old orchards and fountains in the city of Aguascalientes.

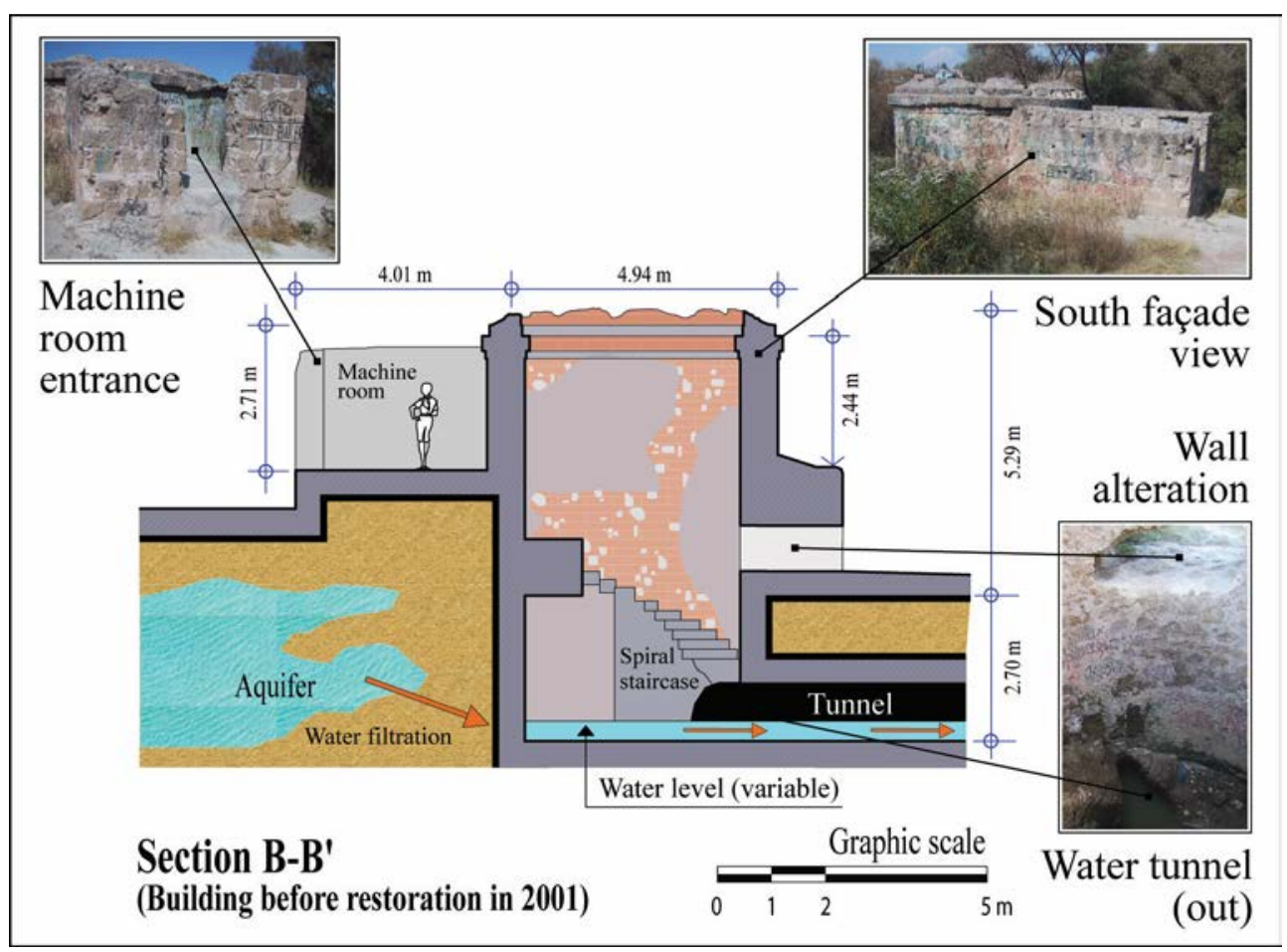

Figure 3: The Caracol water box. Section B-B'. (Source: Restoration Project, photos and drawing by Alejandro Acosta Collazo originally in 2001. Drawing edition: Alejandro Acosta Colunga, August 2019.)

In addition, the idea of building tunnels for water distribution came from Europe to Mexico since the 16th century, but it was during the late 19th century that it became more common. This was also a result of the Industrial Revolution, since it increased production processes, for example the water wheels could power mills. Lacoste says hydraulic revolution became so important that cities started to build water tanks and water tunnels from places away up yonder [5]. Moreover, the social hygiene movement helped improve urbanism at the same time. So, water tunnels became popular and also a very efficient way to maintain the water properties and temperatures similar to its natural sources. The water tunnel system became also useful during the Cristiada War. It was very common to use the water tunnels to escape from one place to another. The Cristiada War took place in Mexico from 1926 to 1929. During this war the government decided to promote a religious intolerance against people during the period of the president Plutarco Elías Calle, whom emphasized separation 
of church and state. So, some priests, social leaders and religious people, as well as some owners of haciendas, decided to build tunnels to communicate churches, haciendas and key houses with exits - around the city - to scape. Nowadays there's confusion between the two types of tunnels, but water tunnels used to be stone masonry tunnels. The case of El Cedazo tunnel had a pointed roof, masonry walls; also it was narrow - the whole way - and had a small channel on the floor.

The types of tunnels used to scape during the Cristiada weren't as good in construction quality as the water tunnels. The Cristiada tunnels were wide and high enough to make people fit - even when riding horses. Nowadays there's not a complete register of such tunnels system. The history of architecture of Aguascalientes registers that one of the most important architects at the beginning of the 20th century: Refugio Reyes drew a plan of the city of Aguascalientes including the whole tunnels system, but the plan hasn't been found in historical archives yet. The fact is that in several constructions in the city centre several tunnels entrances have been found, but none of them are well preserved. In addition, somehow different parts of the tunnels were torn down or demolished on purpose.

From the 16th century to the middle of the 19th century (before the building of El Cedazo tunnel) fresh water was distributed to fountains so people could pick it up and take it in wood buckets to their houses. In fact, most of the people paid water takers whom took carried water on donkeys where people needed it for a few coins.

During the 19th and 20th centuries, some farmers preferred to have donkey wheels to lift subsoil fresh water. This system was known as norias in Mexico. A noria had a rim with wood buckets. Sometimes the norias had an adjacent aqueduct to distribute water to the population of a city. In Guanajuato city there used to be a well-known noria named Noria de Ángeles.

\section{SOCIAL DISTRIBUTION OF FRESH WATER}

There was another type of fresh water distribution, based on subsoil filtration in Aguascalientes. Consequently, some water boxes were built to collect water in tanks for selling it to people. Sandovales historic water supply building is a good example of it. It's located in the north-western side of the city, specifically over the main aquifer in the valley of Aguascalientes state. Because of the decreasing level of water tables this type of water boxes became useless recently. It was in the middle of the 20th century when Sandovales water supply building was constructed, and the owners installed a water pump to lift subsoil water to tanks (see Section A-A' in Fig. 4). The water used to be very clean at this place and it was coming out from a natural source. So, when the tanks were filled up the fresh water was poured in wheel tanks. At the beginning water carts were pulled by donkeys, but in 1960 the system changed to water trucks, as we can observe in Fig. 4.

A few months ago, the author of this article was hired to design a restoration project of Sandovales historic water supply building. One of the main problems to solve was to find out about the spatial changes from the original project, including its adaptations to newer technologies. In fact, this water box was built during the first half of the 20th century. The main changes discovered were the renewal of lines of pipes used in the water box, due to the different types of water pumps acquired by the owners after using the building for several decades.

The population of the city radically increased during the second half of the 20th century and more fresh water was required. Several companies decided to establish in the city and definitely they wanted to distribute fresh water - and also selling it - to the people. Besides San Lorenzo Water Company, Sandovales Water Company turned out to be essential in the northern part of the city as a water distributor. 


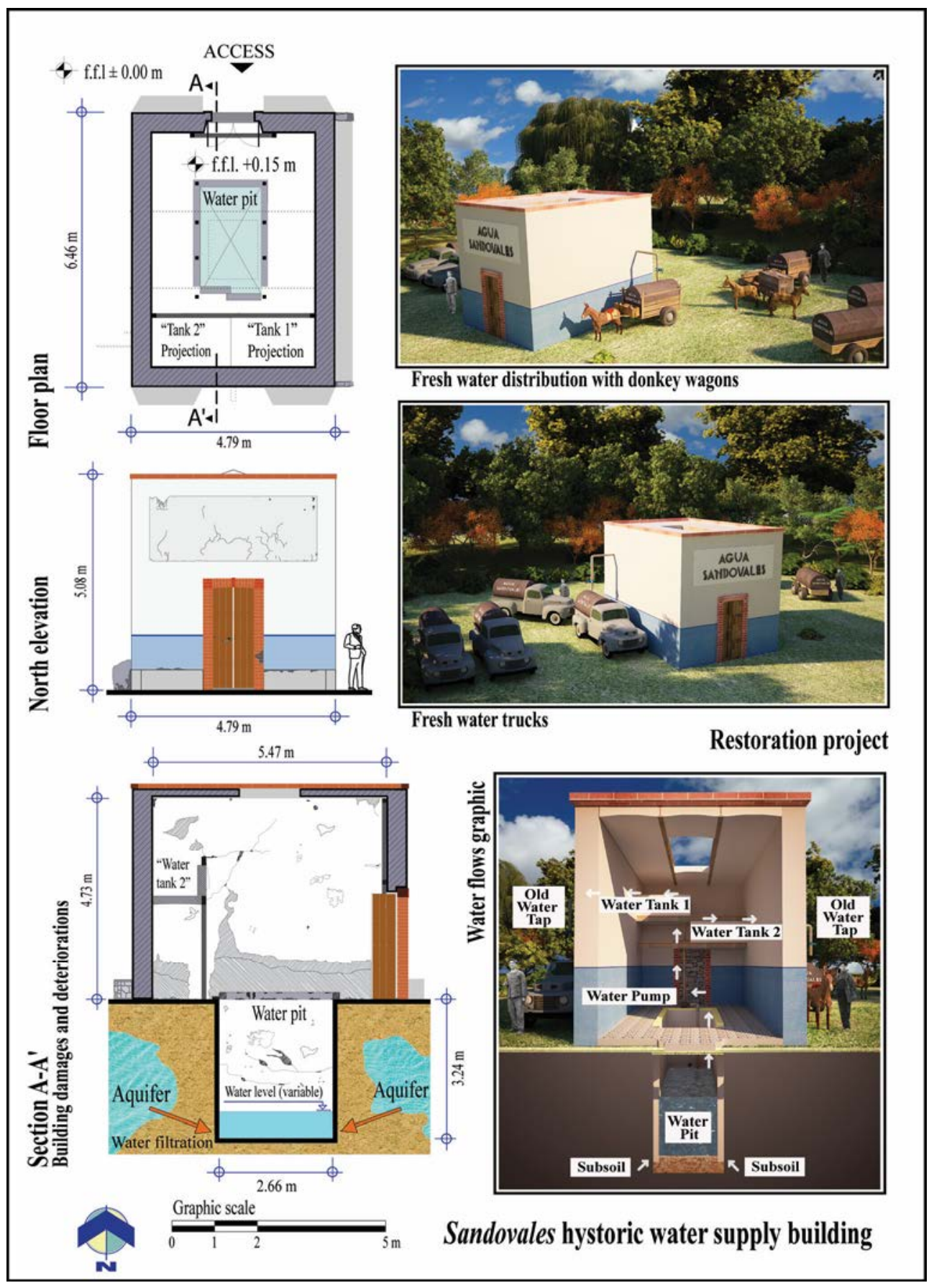

Figure 4: Sandovales historic water supply building in Aguascalientes, Mexico. (Source: Drawing and renders by Alejandro Acosta Collazo, Alejandro Acosta Colunga and Fernando Jesús May Vázquez, August 2019.) 
At first, Sandovales Water Company started distributing fresh water using donkey wagons (see Fig. 4), but during the 1960s they changed them for water trucks. In fact, the water box building had somehow a small size (width $=4.79 \mathrm{~m}$, length $=6.46 \mathrm{~m}$ ) and it was $5.08 \mathrm{~m}$ height. But, a bigger building wasn't necessary because water was like a raw material for the company, and it was taken from the subsoil. Comparing the water boxes mentioned in this paper: Sandovales and El Caracol, we can observe similar architectural dimensions, also the way they filtered ground water, but the distribution of it was different. El Caracol had an adjacent water tunnel (El Cedazo), nevertheless Sandovales water box needed carts to distribute the water to the population. This is a functional response to the moment of time and the geographic place. This means at the end of 19th century motorized vehicles were limited - in quantity - in Aguascalientes. But during the second half of the 20th century they became very popular - over some other means of transportation.

In Sandovales water box the water was pumped up from the subsoil - through a water pit - and poured in tanks. Then using gravity - and through a pipe with a water tap - they filled up the tanks on donkey wagons or water trucks. Also, the time frame between the natural filling of the water pit, with a convenient level, and draining the water tanks was approximately 30 minutes. Thus, the water vehicles could leave the place every 15 minutes because the building had two water tanks and also two water taps.

Urban growth has changed quotidian life in the city since the beginning of the 20th century, but it was in the middle of the century that increasing population started causing urban problems. Population statistics specify that in the year of 1950 the population of Aguascalientes State was: 188,057 people [6], and at the end of the millennium it was close to $1,000,000$ people. The biggest city in the state is Aguascalientes City and it involves $85 \%$ of Aguascalientes State population. Nowadays the city is becoming a million people city.

One of the problems of Aguascalientes growth is pollution and it has affected water quality for several decades. For example, in the year of 1994 a city trash deposit close to Parque México (Mexico Park) was made in the northern side of the city, but it's had a significant impact on the water table, caused by leaching, for the last 25 years. Thus, rain water passed through the trash carrying minerals to ground water. Leaching damages part of the reservoirs of Aguascalientes valley main aquifer. Tiscareño Silva also says leaching from decomposed trash could damage part of Aguascalientes Valley main aquifer due to soil subsidence [7].

Also, the water table tended to fall during the last years because of excess subsoil water extraction. This is somehow due to Aguascalientes urban growth. Thus, the more population live in the city the more fresh water is needed.

El Caracol and Sandovales water box are not functional any more as a result of changes of water table level. This means both buildings are abandoned somehow now.

For the purpose of writing this research, a surveyed was applied recently, to understand the perception of historic use of water and nowadays social distribution of fresh water. The following categories and variables were used: Age (young 13-17, adult 18-60, elderly 60+); gender (male, female); educational level (basic education, graduate, post-graduate); origin (Mexican, foreigner); trust in city's tap water (yes, no); water supply system evaluation (good service, bad service); disappearance of public drinking fountains (water system obsolescence, sanitation control procedures); conscious about El Cedazo water tunnel (yes, no); awareness about water distribution to old orchards (though irrigation ditches, people using water buckets, through pipelines in public streets); reasons of consuming bottled water (the water is clean, it's more practical, flavour) and reasons people don't drink tap water (the water is unclean, because of advertisements). 


\section{RESULTS}

The lack of fresh water in several residential areas of Aguascalientes City is evident, mainly in the eastern neighbourhoods. In some cases the city hall provides only one day of water out of seven every week. El Hidrocálido - a local newspaper - mentions that some people collect rainwater in buckets, during rainy seasons, to use it for bathrooms [8]. This situation becomes more critical every year. Avelar González mentions that extracted water from the water tables has multiplied five times in the last 50 years, so scarcity of fresh water will become a problem to deal with, in the near future [9], especially in semi-arid lands like Aguascalientes.

Nowadays, there's a particular perception of fresh water and its social distribution that will be explained based on the survey designed for this paper.

It's important to mention that, for practical reasons, it was convenient to use only one average resulting table with 25 questionnaires. This means the final table was the average of the five surveyors' results. Thus, five surveyors applied 120 questionnaires apiece. The total amount of questionnaires was 600, during the first week of August. But, a sample of 125 questionnaires was chosen using a random method ( 25 questionnaires respectively). This means the final table was the average of the five surveyors' random results.

The average table (not included in this paper) was used to develop a Burt's matrix, and involves all the categories and the 26 variables of the questionnaire. In order to create the matrix shown in Table 1 a transposed matrix (not included in this paper) was done, and the result (Burt's matrix $=Z^{\prime} Z$ ) was the average matrix times the transposed matrix.

The results demonstrated that in the category of trust in city's tap water, the people with more participation were adult females and $87 \%$ mentioned they didn't trust in city's tap water. But $48 \%$ of people with basic education also said they didn't trust in city's tap water, similarly, $36 \%$ of people (graduated) thought the same way.

In the category: Water supply system evaluation, the people who participated were basically adults $(92 \%)$, and $78 \%$ of them were happy with the water system. Although some of them asked the surveyors if there was another variable (other than good service or bad service) because some of them thought the service had a more or less quality.

The awareness of people about historic water systems in the city had to do with the disappearance of public drinking fountains. $76 \%$ of people thought public drinking fountains had disappeared because of sanitation control procedures, which is in some measure correct.

In the results of the survey, the conscious about El Cedazo water tunnel was basically negative. Thus, $92 \%$ of the people denied understanding the presence of the historic water tunnel. Therefore, this situation should be a concern in the accomplishments of Aguascalientes preservation programs.

The classification: Awareness about water distribution to old orchards in the city, was more related to historical facts, specifically if people knew if water was distributed through irrigation ditches, or if people used water buckets in the past to flood the orchards, or the city hall used pipelines in public streets to distribute the water. $84 \%$ of the people mentioned that distribution to orchards was done through irrigation ditches.

Consuming bottled water is a concern of the author of this paper because it looks like nobody knows if tap water in the city is really clean, but bottled fresh water distribution companies say it isn't. So, $52 \%$ of the adult people said they consumed bottled water because it was clean and $40 \%$ because it's more practical. People are always in a rush, and acquiring bottled fresh water means less time consuming.

The reasons people don't drink tap water have to do with a healthy perception. Since tap water is distributed sometimes through rusty pipelines they think it's unclean. $80 \%$ of the people said the main reason for not drinking this type of water was because it's unhygienic and only $12 \%$ mentioned the reason was the advertisements. 
Table 1: Data obtained from 650 questionnaires applied in public spaces of Aguascalientes City, and converted in matrixes to develop a Burt's matrix. (Source: Author research design, August, 2019.)

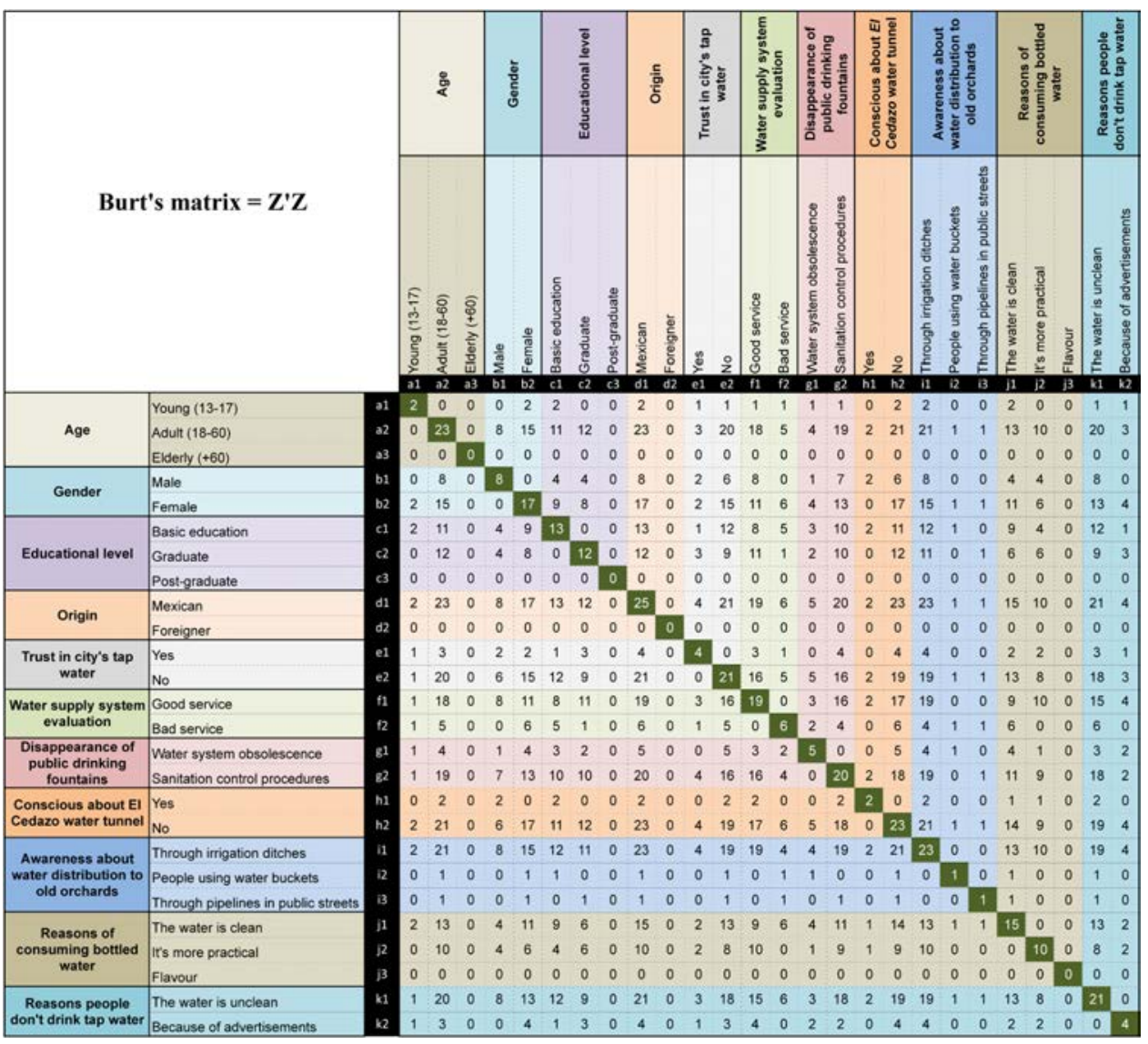

\section{DISCUSSION}

The water supply buildings shown in this paper were in harmony between water distribution and built forms; also they were good examples of Viceroyalty water boxes in Mexico. But social water distribution has changed in the last decades and people have forgotten what water historic buildings were made for. People now are more worried if there's no water from pipelines. Also, watching TV has changed the perceptions of people, specifically on the way we have to consume products like bottled fresh water.

After analysing the results of the survey applied for this paper, we can observe that most of the people don't trust in city's tap water, so they prefer to drink bottled water. Similarly, a couple of tourists - in a Mexican tourist group - mentioned they preferred bottled fresh water and mentioned, in their countries, every once in a while, they had watched advertisements saying "don't drink the water in Mexico". In addition, even more educated people in Mexico don't trust in tap water, accordingly with the foreigners' perception.

Even though a company administrates social ground water distribution - by pipelines in streets - it was demonstrated in the survey that most of the adult people (78\%) think they get a good service. 
The answers about water distribution to old orchards in general were reasonable. This means people are aware of this type of water distribution. In fact, nowadays irrigation in the countryside is still through water ditches.

Even though city orchards are disappearing due to urban growth they used to be an essential aspect of the city image during the 19th century and in the early 20th century.

The correspondence analysis allows a comparison among all variables resulting in interesting discussions. For example, a few people think that nowadays water supply system is good, and also think disappearance of public drinking fountains had to do with water system obsolescence. This means they prefer to practice renovation beliefs over a preservation culture.

\section{CONCLUSIONS}

History of ground water distribution is related to historical thermal water distribution in Aguascalientes (a hot waters city). De Groot says that it seems that historians wish to mark history out, to control and boundarise it, but it is in the transformations and transgressions of the historical that culture's desires, innermost workings, and underlying assumptions might be seen [10], so describing history of unique buildings should be related to scientific basis. This is the case of El Caracol or Sandovales water boxes, and the restoration projects made to understand the original spatial functions of the buildings.

There's still job to do, registering and drawing the complete tunnels system in Aguascalientes. Also preservationists should prevail over renewal ideas about historical buildings.

Also, the survey and the qualitative statistical method used in this paper (Burt's matrix) showed interesting results. For example, in the category: Water supply system evaluation, most of the people who participated in the survey were happy with the water system currently. This result was a surprise, due to the negative perception of local news.

It was remarked in this article - through research - that historic water boxes didn't function anymore because of nowadays low level water tables, and because of subsidence problems. So it looks like we - as researchers - need to share this type of knowledge among society. Accordingly, science could contribute to veracity of press news as long as they consult science. This means there should be more interaction between news and science.

In addition, the fresh water companies have changed the perception of tap water quality in Mexico for the last two decades. Most people had an embracing image about bottled water, especially if global enterprises distributed it.

Besides, in Mexico we have a problem with sugary drinks, because most of the people drink them to hydrate. This is common in young and adult people. For example, it's usual that construction workers drink sugary drinks instead of water, this means about half a gallon a day. Then it becomes a healthy problem, so obesity and diabetics are very excessive in Mexican population.

Education (public or private) should contribute to understand the use of water and the consequences of consuming sugary drinks or bottled water. Also, science and ethical news could help with it. Additionally, subjects about sustainability should be included in schools in order to understand the way we have historically used water, and what we are doing with it nowadays.

Finally, water is a common element that connects species throughout millenniums, including prehistoric and the whole history of human beings, and there's still a lot to do in order to preserve it. 


\section{ACKNOWLEDGEMENTS}

I thank my research assistants Jéssica Alejandra Rodríguez Torres, Tania Judith Pedroza Díaz and Alejandro Acosta Colunga. I also thank the students Fernando Jesús May Vázquez, Ricardo Daniel Alfaro Ake, Norma Elena Alemán López, Sandra Nallely González Robles, Leopoldo Madrigal Muñoz, Mauricio Rivera Garza, María Fernanda Pérez Sifuentes and Ana Karen Gutiérrez García. Appreciation is extended to my colleague and researcher Marco Alejandro Sifuentes Solís.

\section{REFERENCES}

[1] Acosta Collazo, A., Urban mobility and qualitative research in historic places. WIT Transactions on The Built Environment, vol. 182, WIT Press: Southampton and Boston, pp. 267-283, 2019. DOI: 10.2495/UT1743-3509.

[2] Josse, J., Husson, F. \& Lê, S., Multiple Correspondence Analysis, Applied Mathematics Department: Dortmund, p. 7, 2008.

[3] Ruiz López, A.L., Public Charity Bureau and Poor People in Aguascalientes, 18711942, ICA: Aguascalientes, pp. 68-69, 2013.

[4] Guzmán Gutiérrez, J.R. \& Acosta Rincón, O.E., Aguascalientes en la Prehistoria. Un testimonio del pasado remoto de nuestro Estado. Tercer Certamen Histórico Literario, Ayuntamiento de Aguascalientes: Aguascalientes, pp. 29-33, 1994.

[5] Lacoste, Y., The Water: The Fight for Life, Larousse: Barcelona, p. 29, 2003.

[6] INEGI, 100 Years of Population Census in Mexico, INEGI: Aguascalientes, p. 68, 1996.

[7] Tiscareño Silva, R., Trash impact in Aguascalientes City. Investigación y Ciencia, 18, p. 56, 1996.

[8] El Hidrocálido, Aguascalientes, 6 Jul., p. 5, 2019.

[9] Avelar González, F.J., Aguascalientes, El Hidrocálido, 14 Jun., p. 2, 2019.

[10] De Groot, J., Consuming History: Historians and Heritage in Contemporary Popular Culture, Routledge: Oxford and New York, p. 250, 2009. 